\title{
Effect of propolis gel on the in vitro reduction of dentin permeability
}

\author{
Silvia Helena de Carvalho SALES-PERES ${ }^{1}$, Flávia Negreiros de CARVALHO², Juliane Avansini MARSICANO³, \\ Maria Cecília MATTOS ${ }^{4}$, José Carlos PEREIRA ${ }^{5}$, Moacir Rossi FORIM ${ }^{6}$, Maria Fatima das Graças Fernandes da SILVA ${ }^{6}$
}

\footnotetext{
1- DDS, MSc, PhD, Department of Pediatric Dentistry, Orthodontics and Community Health, Bauru School of Dentistry, University of São Paulo, Bauru, SP, Brazil. 2- DDS, Department of Pediatric Dentistry, Orthodontics and Community Health, Bauru School of Dentistry, University of São Paulo, Bauru, SP, Brazil.

3- DDS, MSc, Department of Pediatric Dentistry, Orthodontics and Community Health, Bauru School of Dentistry, University of São Paulo, Bauru, SP, Brazil.

4- DDS, MSc, Department of Operative Dentistry, Endodontics e Dental Materials, Bauru School of Dentistry, University of São Paulo.

5- DDS, MSc, PhD, Department of Operative Dentistry, Endodontics e Dental Materials, Bauru School of Dentistry, University of São Paulo.

6- PhD, Department of Chemistry, Laboratory of Natural Products, Federal University of São Carlos, São Carlos, SP, Brazil.
}

Corresponding address: Silvia Helena de Carvalho Sales-Peres - Faculdade de Odontologia de Bauru - USP - Departamento de Odontopediatria, Ortodontia e Saúde Coletiva - Disciplina de Saúde Coletiva - Al. Octávio Pinheiro Brisolla, 9-75 - Bauru-SP - 17012-901 - Phone: +55-14-32358260 - Fax +55-14-32358260 - e-mail: shcperes@usp.br

Received: September 16, 2009 - Modification: February 16, 2010 - Accepted: May 25, 2010

\section{ABSTRACT}

$\mathrm{O}$ bjective: The aim of this study was to evaluate the capacity of potassium oxalate, fluoride gel and two kinds of propolis gel to reduce the hydraulic conductance of dentin, in vitro. Material and Methods: The methodology used for the measurement of hydraulic conductance of dentin in the present study was based on a model proposed in literature. Thirty-six 1-mm-thick dentin discs, obtained from extracted human third molars were divided into 4 groups $(n=9)$. The groups corresponded to the following experimental materials: GI-10\% propolis gel, $\mathrm{pH} 4.1$; GII-30\% propolis gel; GIII-3\% potassium oxalate gel, pH 4,1 ; and GIV-1.23\% fluoride gel, $\mathrm{pH} 4.1$, applied to the dentin under the following surface conditions: after $37 \%$ phosphoric acid and before $6 \%$ citric acid application. The occluding capacity of the dentin tubules was evaluated using scanning electron microscopy (SEM) at $\times 500, \times 1,000$ and $\times 2,000$ magnifications. Data were analyzed statistically by two-way ANOVA and Tukey's test at 5\% significance level. Results: Groups I, II, III, IV did not differ significantly from the others in any conditions by reducing in hydraulic conductance. The active agents reduced dentin permeability; however they produced the smallest reduction in hydraulic conductance when compared to the presence of smear layer $(P<0.05)$. The effectiveness in reducing dentin permeability did not differ significantly from $10 \%$ or $30 \%$ propolis gels. SEM micrographs revealed that dentin tubules were partially occluded after treatment with propolis. Conclusions: Under the conditions of this study, the application of $10 \%$ and $30 \%$ propolis gels did not seem to reduce the hydraulic conductance of dentin in vitro, but it showed capacity of partially obliterating the dentin tubules. Propolis is used in the treatment of different oral problems without causing significant great collateral effects, and can be a good option in the treatment of patients with dentin sensitivity.

Key words: Dentin. Dentin permeability. Dentin sensitivity. Propolis.

\section{INTRODUCTION}

Dentin hypersensitivity is a clinical condition of difficult treatment because its complex etiology has not yet been clearly understood. Although several hypotheses have been proposed to explain the mechanism of dentin hypersensitivity, it is still unclear how the stimuli applied to the external dentin surface may stimulate nerve fibers ${ }^{20,22}$.
The hydrodynamic theory of dentin hypersensitivity states that the movement of fluid within the dentin tubules is the mechanism by which pain is experienced when the exposed dentin is stimulated ${ }^{5}$. Occlusion of the patent dentin tubules would appear to be essential for the treatment success ${ }^{13}$.

Occlusive hypersensitivity treatments were proposed to obliterate surface dentin to reduce the movement of fluids into the tubules and the 
pain ${ }^{1}$. Oxalate base and fluoride are indicated substances for the treatment of this problem ${ }^{23}$. Oxalate desensitization has been shown both in vitro ${ }^{8,29}$ and in vivo ${ }^{9,18}$ to be effective in reducing the permeability of deeply acid-etched dentin. Oxalate products reduce dentin permeability and occlude tubules more consistently in laboratory studies ${ }^{8}$ than they do in clinical trials ${ }^{20}$. Fluoride such as sodium fluoride and stannous fluoride can reduce dentin sensitivity ${ }^{17}$. Fluorides decrease the permeability of dentin in vitro ${ }^{10}$, possibly by precipitation of insoluble calcium fluoride within the tubules.

Some studies with laser therapy for dentin hypersensitivity present favorable results as GaAIAs laser, so may be another treatment option ${ }^{14,19}$. However, there has been controversy on the efficacy of low-level lasers for this purpose, opening space for new research works?

Several agents and therapies have been proposed for the treatment of the hypersensitivity, but none of them has been proven completely efficient for such use ${ }^{25}$, and the development of new desensitizing agents is needed.

Propolis has been shown to have antimicrobial, anti-tumor, anesthetic, anti-inflammatory, anti-viral and healing properties ${ }^{11,16}$. A different research has shown that propolis can treat and control the dental caries ${ }^{12}$, accelerate and facilitate the healing of oral tissue $^{15}$, reduce the pulp inflammation ${ }^{26}$, with no major side effects.

Propolis is a natural, non-toxic resin produced by honey bees that has been used for hundreds of years ${ }^{6}$ and presents a complex composition depending basically on the plant sources accessible to the bees, possessing a variety of biological and pharmacologic activities, attracting the interest of an increasing number of researchers ${ }^{27}$. Brazilian samples present striking differences in their chemical composition when compared to samples from temperate zones ${ }^{27}$.

The main compounds found in propolis are distributed in several major classes: phenolic acids and their esters, flavonoids (flavones, flavonones, flavonols, dihydroflavonols, chalcones), terpenes, $\beta$ steroids, aromatic aldehydes, alcohols, sesquiterpenes, naphthalene, stilbene derivatives of benzopyran, benzophenone, caffeic acid, cinnamic acid derivatives, and benzoic acid 6 .

Considering that only few studies have assessed the effect of propolis extracts on dentin permeability, the aim of this in vitro study was to evaluate the variation in the reduction of hydraulic conductance of dentin after treatment with two different propolis gels, potassium oxalate and acidified fluorophosphates gel. The tested null hypothesis was that the propolis gels do not reduce the hydraulic conductance of dentin or cause similar reduction to that of as potassium oxalate and acidified fluorophosphates.

\section{MATERIAL AND METHODS}

\section{Ethical aspects}

This research was approved by the Research Ethics Committee of Bauru School of Dentistry, University of São Paulo (protocol \#110/2007). The teeth used in this study are obtained from the Human Tooth Bank of Bauru School of Dentistry.

\section{Selection of teeth and specimen preparation}

Freshly extracted human teeth are a potential source of biological pathogens ${ }^{24}$. Extracted human third molars were stored at $4^{\circ} \mathrm{C}$ in $0.1 \%$ thymol (Merck KGaA, Frankfurter Str, Darmstadt, Germany) to inhibit microbial growth and were used within 1 month after extraction.

The crowns were sectioned with a diamond disc in a sectioning machine (Isomet 1000; Buehler, Lake Bluff, IL, USA) perpendicular to the long axis of the roots, to create dentin discs from mid coronal dentin. Forty-six dentin discs were obtained, planned and polished with 400-600 grit SiC paper (Buehler), resulting in dentin discs of approximately $0.98 \pm 0.08$ $\mathrm{mm}$ thick, as measured by a micrometer accurate to $0.01 \mathrm{~mm}$. The disc surface was free of enamel and with no evidence of pulp horns.

After discarding discs with enamel, pulp horns and measuring less than $1 \mathrm{~mm}$ thick, the selected discs had their permeability measured. All 36 specimens used in this study presented the same range of permeability in an attempt to reduce possible errors of research.

\section{Procedures}

Dentin permeability was measured by the filtration of water and expressed in terms of hydraulic conductance using a method suggested by Pashley and Galloway ${ }^{23}$ (1985). The deionized water filtration through the dentin was measured after each of the following situations: using 320-grit $\mathrm{SiC}$ in a rotating polisher $(125 \mathrm{rpm})$ for $5 \mathrm{~s}$, a standard smear layer was produced on the occlusive surface of the discs, representing the minimum permeability; after smear layer removal with phosphoric acid at $37 \%$ for 1 min to obtain the maximum permeability; after 4 min of passive application of desensitizing agents; after application of $6 \%$ citric acid (Merck KGaA, Frankfurter Str, Darmstadt, Germany) for 1 min, to determine how susceptible the treatment was to acid challenge.

The other values, including the effects of gel and smear layer, were calculated as a proportion of $100 \%$ permeability. After maximum permeability was determined, the desensitizing agents were applied to dentin disc surface for $4 \mathrm{~min}$, and thoroughly rinsed with deionized water. The filtration measurement was made for each condition and the relative percentage to maximum permeability was calculated using the 
following equation: $L P=Q / P(S A)$, where $L p=$ hydraulic conductance of dentin in $\mu \mathrm{L} \mathrm{cm}^{-2} \mathrm{~min}^{-1} \cdot \mathrm{CmH}_{2} 0$; $\mathrm{Q}=$ filtration rate in $\mu \mathrm{L} \min ^{-1} ; \mathrm{SA}=$ surface area in $\mathrm{cm}^{2} ; \mathrm{P}=$ hydrostatic pressure through dentin in $\mathrm{H}_{2} \mathrm{O}$ $\mathrm{cm}$. The velocity and time of bubble movement were considered as variable and the capillary volume and internal diameter, the hydrostatic pressure and the surface area were constant.

\section{Materials and experimental conditions}

The 36 dentin discs were randomly divided into 4 groups of 9 specimens each, corresponding to two experimental materials ( $10 \%$ and $30 \%$ propolis), Oxa-gel and Fluoride gel $1.23 \%$, in conditions of pretreatment surface. The materials used are listed in Figure 1 . The Oxa-gel and $1.23 \%$ fluoride gel were used as a control group as in other studies ${ }^{3,28}$ on treatment for dentin sensitivity.

All desensitizing agents were applied for $4 \mathrm{~min}$, to follow the manufacturer's instructions for OxaGel, and then rinsed with deionized water. After the hydraulic conductance was measured under the conditions described above, the specimens were exposed to $6 \%$ citric acid $\mathrm{pH} 2.1$ for $1 \mathrm{~min}$ and the filtration was measured again. This treatment aimed to evaluate the resistance of the eventual occlusive effect of the studied materials to an acid environment, similar to the one found in the mouth. The hydraulic conductance of each condition was determined four times in succession and the average value was determined and expressed as the percentage of the maximum Lp.

\section{Scanning electron microscopy (SEM)}

The samples were fastened in a metal sample support using a ribbon of carbon. After fastening, the samples were conditioned in a vacuum desiccator for water evaporation. Once dried, they were covered with a fine layer of gold ( $50 \mathrm{~nm}$ ) to be analyzed by scanning electron microscopy (SEM; Zeiss, DSM940A, Germany) 20 kV, SEM micrographs were obtained at magnifications of $\times 500, \times 1,000$ and $\times 2,000^{21}$.

\section{Statistical analysis}

Statistica 7.0 software (Stat Soft, Tulsa, OK, USA) was used, and a 5\% alpha was assumed for statistical significance. The data were tested by twoway analysis of variance, applied to the reductions in hydraulic conductance in order to detect differences between the studied conditions. For individual comparisons among the groups, the Tukey's test was used.

\section{RESULTS}

Table 1 shows the mean hydraulic conductance ( \pm standard deviation) of the groups. The desensitizing effect was observed for all groups ( $G I=0.16 \pm 0.06$; $\mathrm{GII}=0.24 \pm 0.06$; GIII=0.17 $\pm 0.06 ; \mathrm{GIV}=0.21 \pm 0.11$ ), which had very similar behavior and did not significantly differ from each other.

\begin{tabular}{|c|c|c|c|}
\hline Material & $\mathrm{pH}$ & Components & Manufacturing \\
\hline $10 \%$ Propolis gel & 4.1 & $\begin{array}{c}\text { Alcoholic extract of } \\
10 \% \text { Propolis }\end{array}$ & Manipulation \\
\hline $30 \%$ Propolis gel & 4.1 & $\begin{array}{c}\text { Alcoholic extract of } \\
30 \% \text { Propolis }\end{array}$ & Manipulation \\
\hline OXA-GEL & 4.1 & $\begin{array}{c}3 \% \text { Potassium } \\
\text { oxalate monohydrate } \\
\text { carboxymethylcellulose }\end{array}$ & FGM- BRAZIL \\
\hline Acidulated & 4.1 & $\begin{array}{c}1.23 \% \text { Acidulated } \\
\text { fluorophosphate }\end{array}$ & Manipulation \\
\hline
\end{tabular}

Figure 1- Material used to treat the dentin surface

Table 1- Means [ \pm standard deviation (SD)] of hydraulic conductance for each gel type after acid challenge as well as minimum and maximum (100\%) hydraulic conductance

\begin{tabular}{|c|c|c|c|c|c|c|c|c|}
\hline & \multicolumn{2}{|c|}{$\begin{array}{c}10 \% \\
\text { PROPOLIS }\end{array}$} & \multicolumn{2}{|c|}{$\begin{array}{c}30 \% \\
\text { PROPOLIS }\end{array}$} & \multicolumn{2}{|c|}{ OXA-GEL } & \multicolumn{2}{|c|}{ FLUORIDE } \\
\hline & mean $\pm S D$ & $\%$ & mean $\pm S D$ & $\%$ & mean $\pm S D$ & $\%$ & mean $\pm S D$ & $\%$ \\
\hline Maximum & $0.16 \pm 0.6$ & 100.0 & $0.25 \pm 0.6$ & 100.0 & $0.21 \pm 0.09$ & 100.0 & $0.23 \pm 0.12$ & 100.0 \\
\hline Minimum & $0.03 \pm 0.04$ & 17.6 & $0.09 \pm 0.08$ & 38.4 & $0.03 \pm 0.04$ & 11.5 & $0.01 \pm 0.01$ & 8.7 \\
\hline Gel & $0.16 \pm 0.06$ & 97.1 & $0.24 \pm 0.06$ & 95.2 & $0.17 \pm 0.06$ & 82.6 & $0.21 \pm 0.11$ & 92.5 \\
\hline Acid challenge & $0.16 \pm 0.07$ & 98.5 & $0.23 \pm 0.06$ & 94.6 & $0.16 \pm 0.06$ & 80.9 & $0.20 \pm 0.11$ & 89.1 \\
\hline
\end{tabular}



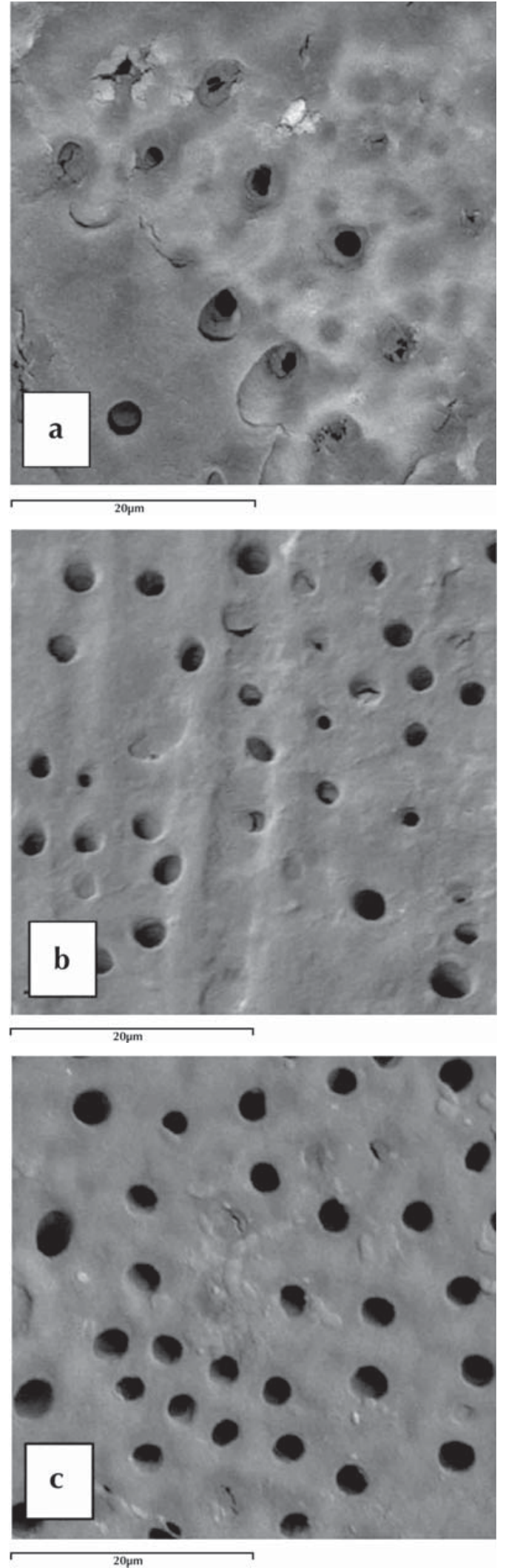

Figure 2- Representative scanning electron microscopy micrograph of dentin surface (a) before immersion in the acid solution, in the presence of smear layer; (b) after immersion in acid solution and treatment with $10 \%$ propolis gel; (c) after immersion in acid solution and treatment with $30 \%$ propolis gel
The effectiveness of gels for dentin permeability reduction was analyzed to ANOVA by two-criteria $(P>0.05)$. The data showed no significant difference among the gels $(P=0.145)$.

The results showed that although the procedures have caused some reduction in the hydraulic conductance of dentin after were submitting to the phosphoric acid, they did not present significant reduction $(P>0.05)$.

The hydraulic conductance presented significant difference when to compare the smear layer and tested gels $(P=0.00)$. After challenge acid, the analysed gels did not reveal differences among them $(P>0.05)$.

SEM was used to observe the morphology surface of the samples after treatment with the $10 \%$ and $30 \%$ propolis gels. The SEM micrographs revealed that the dentin tubules were partially obliterated by crystalline deposits formed inside the dentin tubules after using the propolis gels. When the $10 \%$ propolis gel was applied in dentin the surface showed more homogeneous, probably due to two actions, one obliterates of tubules and another deposits on dentin superficial (Figures 2a, 2b and 2c).

The $10 \%$ propolis gel, a more homogeneous dentin surface was observed, probably because the deposits and partially obliterations of the superficial altered dentin tubules (Figures $2 a, 2 b$ and $2 c$ ). On the other hand, the $30 \%$ propolis gel seems to only partially obliterate the dentin tubules $(P<0.05)$.

\section{DISCUSSION}

It is clear that in vivo experiment is the ideal methodology for biological investigation and in vitro studies can only address limited aspects of any natural system. In this in vitro study, the device applied to the assessment of dentin hydraulic conductance requires the use of a certain pressure for movement system and further measurement of dentin permeability. An increasing intra-tubular resistance may occur under high pressures due to the compression of internal tubule contents against tubule walls, reducing the values of hydraulic conductance. The Lp values were expressed as percentages of maximum hydraulic conductance (Lp), where each disc has its own control. On the other hand, the minimum permeability can be represented as the Lp associated with the presence of a smear layer. Maximum permeability was achieved by removing the smear layer using $37 \%$ phosphoric acid. Maximum permeability values were considered $100 \%$ of each specimen's filtration. The other values, including the effects of different gels and the smear layer, were calculated as a proportion of $100 \%$ permeability ${ }^{28}$.

In the present study, dentin permeability was similar in all the groups. The Oxa-gel, fluoride 
gel, $10 \%$ propolis and $30 \%$ propolis gels indicated minimal reduction of dentin hydraulic conductance when compared to smear layer $(P>0.05)$.

Potassium oxalate has been reported in a number of publications ${ }^{21}$ as an effective treatment for occluding dentin tubules. From the published data, it can be noticed that, in general, potassium oxalate-based agents act reducing the fluid flow in similar proportions to the minimum permeability (smear layer) ${ }^{28,30}$. In contrast to most studies, our results indicated significant difference between Oxa-gel and smear-layer in terms of permeability reduction $(P<0.05)$. Fluoride gel, and $10 \%$ and $30 \%$ propolis gels differed significantly from smear layer $(P<0.05)$. These results indicate that as other agents desensibilizantes ${ }^{28}$, oxa-gel, fluor gel and propolis gels have an effective track for hypersensitive dentin when compared with smear layer, which was considered as the agent that could obliterate all dentin tubules.

The present study showed that the gels were not able to reduce the permeability in vitro due to a significant difference between smear layer and tested gels $(P=0.00)$. The data should be considered with reserve, due the low reduction the hydraulic conductance in dentin permeability promotion by all gels tests.

Citric acid application after gel was done to simulate the resistance to acid challenge caused by acid foods and drinks in the oral environment. The results did not show any significant difference among the four groups after application of citric acid, which reinforce the hypothesis that all tested gels offered some resistance to the acid challenge, although they were not effective in minimizing the dentin permeability.

Research on the properties of propolis for oral applications has shown that it has an antiinflammatory action and stimulates reparative dentin formation ${ }^{16}$, which could be able to reduce the dentin permeability. Thus, it can be extrapolated the benefit of propolis gels in dentin, due to the action similar to Oxa-gel.

According to the hydrodynamic theory, treatments for hypersensitivity should occlude dentin tubules and prevent nerve sensitivity ${ }^{4}$. The propolis gel acts obliterating dentin tubules, then the permeability is also decreased, reducing dentin hypersensitivity.

Andrade e Silva² (2007) tested the effects of sequential application of potassium oxalate gel/ adhesive agent on in vitro dentin permeability, using the Flodec. It was concluded that the use of potassium oxalate gel was effective in reducing the permeability of bonded dentin. Other studies have been conducted using Flodec for determining propolis action on the dentin permeability.

The application of an acid oxalate solution to form small insoluble crystals of calcium oxalate within dentin tubules and thus, restrict fluid movement across dentin, has been used in clinical dentistry to desensitize dentin ${ }^{2}$. The two propolis gels analyzed (10\% or $30 \%)$, did not have significant difference. The SEM analysis showed that the two concentrations present different action mechanisms in the dentin surface. The $30 \%$ propolis gel produced a more homogeneous dentin surface, probably due to the obliteration of the superficial dentin tubules. However, the $10 \%$ propolis gel beyond partially obliterates the tubules and deposits on dentin surface. These findings must be interpreted as the lower concentration (10\% propolis) can be used in dentin.

The obliteration of tubules when the $10 \%$ propolis gel was used can be due to the interaction of components of propolis, how flavonoids may interact with the dentin, thus forming crystals that reduce fluid movement within dentin and, consequently, reduce dentin sensibility. This theory was based the study by Sabir, et al ${ }^{26}$ (2005), in which direct pulp capping was performed with propolis-derived flavonoids and mild and moderate inflammation was seen in the pulp chamber at week 2 and 4, and partial dentin bridge formation was detected beneath the pulp-capping material at week 4.

Another hypothesis for the better obliteration of dentin tubules after treatment with $10 \%$ propolis gel, when compared to other test gels, could be that it is more fluid, which allows the easiest access of tubules and thus a greater interaction with exposed dentin. Propolis has different therapeutic properties without causing major side effects $11,12,15,16,26$ and can be a good option in the treatment of patients with dentin sensitivity. Further ex-vivo and in vivo studies should be conducted to clarify the real action and beneficial effects of propolis for the treatment of dentin permeability.

\section{CONCLUSIONS}

The present results suggest that both $10 \%$ and $30 \%$ propolis gels do not seem to reduce the dentin permeability as smear layer, the best method to obliterate dentin tubules. However, propolis is a natural product and it can be used for partially obliterating the exposed human dentin as its effects are similar to those of potassium oxalate gel and fluoride gel. Propolis gels demonstrated same performance in reducing dentin permeability, due to relatively precipitation and partial sealing of the dentin tubules. 


\section{REFERENCES}

1- Absi EG, Addy M, Adams D. Dentine hypersensitivity: uptake of toothpastes onto dentine and effects of brushing, washing and dietary acid--SEM in vitro study. J Oral Rehabil. 1995;22:175-82. 2- Andrade e Silva SM, Marquezini L Jr., Manso AP, Garcia FP, Carrilho MR, Pashley DH, et al. Effects of a combined application of potassium oxalate gel/adhesive agent on dentin permeability in vitro. J Adhes Dent. 2007;9:505-12.

3- Aranha AC, Pimenta LA, Marchi GM. Clinical evaluation of desensitizing treatments for cervical dentin hypersensitivity. Braz Oral Res. 2009;23:333-9.

4- Arrais CAG, Chan DCN, Giannini M. Effects of desensitizing agents on dentinal tubule occlusion. J Appl Oral Sci. 2004;12:1448.

5- Brännström M, Lindén LA, Aström A. The hydrodynamics of the dental tubule and of pulp fluid. A discussion of its significance in relation to dentinal sensitivity. Caries Res. 1967;1:310-7.

6- Castro ML, Nascimento AM, Ikegaki M, Costa-Neto CM, Alencar $\mathrm{SM}$, Rosalen PL. Identification of a bioactive compound isolated from Brazilian propolis type 6. Bioorg Med Chem. 2009;17:5332-5. 7- Gentile LC, Greghi SLA. Clinical evaluation of dentin hypersensitivity treatment with the low intensity GalliumAluminum-Arsenide laser - AsGaAl. J Appl Oral Sci. 2004;12:26772.

8- Gillam DG, Mordan NJ, Sinodinou AD, Tang JY, Knowles JC, Gibson IR. The effects of oxalate-containing products on the exposed dentine surface: an SEM investigation. J Oral Rehabil. 2001;28:1037-44.

9- Gillam DG, Newman HN, Davies EH, Bulman JS, Troullos ES, Curro FA. Clinical evaluation of ferric oxalate in relieving dentine hypersensitivity. J Oral Rehabil. 2004;31:245-50.

10- Greenhill JD, Pashley DH. The effects of desensitizing agents on the hydraulic conductance of human dentin in vitro. J Dent Res. $1981 ; 60: 686-98$.

11- Ikeno K, Ikeno T, Miyazawa C. Effects of propolis on dental caries in rats. Caries Res. 1991;25:347-51.

12- Koo H, Vacca Smith AM, Bowen WH, Rosalen PL, Cury JA, Park YK. Effects of Apis mellifera propolis on the activities of streptococcal glucosyltransferases in solution and adsorbed onto saliva-coated hydroxyapatite. Caries Res. 2000;34:418-26.

13- Krauser JT. Hypersensitive teeth. Part II: treatment. J Prosthet Dent. 1986;56:307-11.

14- Ladalardo TC, Pinheiro A, Campos RA. Brugnera A Jr, Zanin $\mathrm{F}$, Albernaz $\mathrm{PL}$, et al. Laser therapy in the treatment of dentine hypersensitivity. Braz Dent J. 2004;15:144-50.
15- Magro O Filho, Carvalho AC. Topical effect of propolis in the repair of sulcoplasties by the modified Kazanjian technique. Cytological and clinical evaluation. J Nihon Univ Sch Dent. 1994;36:102-11.

16- Marcucci MC. Propolis: chemical composition, biological properties and therapeutics activity. Apidologie. 1995;26:83-99. 17- Morris MF, Davis RD, Richardson BW. Clinical efficacy of two dentin desensitizing agents. Am J Dent. 1999;12:72-6.

18- Muzzin KB, Johnson R. Effects of potassium oxalate on dentin hypersensitivity in vivo. J Periodontol. 1989;60:151-8.

19- Noya MS, Bezerra RB, Lopes JL, Barbosa AL. Clinical evaluation of the immediate effectiveness of GaAIAs laser on the therapy of dentin hypersensitivity. J Appl Oral Sci. 2004;12:363-6.

20- Orchardson R, Gillam DG. The efficacy of potassium salts as agents for treating dentin hypersensitivity. J Orofac Pain. 2000;14:9-19.

21- Pashley DH. Dentin: a dynamic substrate--a review. Scanning Microsc. 1989;3:161-74.

22- Pashley DH. Mechanisms of dentin sensitivity. Dent Clin North Am. 1990;34:449-73.

23- Pashley DH, Galloway SE. The effects of oxalate treatment on the smear layer of ground surfaces of human dentine. Arch Oral Biol. 1985;30:731-7.

24- Preston KP, Higham SM, Smith PW. The efficacy of techniques for the disinfection of artificial sub-surface dentinal caries lesions and their effect on demineralization and remineralization in vitro. J Dent. 2007;35:490-5.

25- Rosing CK, Fiorini T, Liberman DN, Cavagni J. Dentine hypersensitivity: analysis of self-care products. Braz Oral Res. 2009;23(sp. issue 1):56-63.

26- Sabir A, Tabbu CR, Agustiono P, Sosroseno W. Histological analysis of rat dental pulp tissue capped with propolis. J Oral Sci. 2005;47:135-8.

27- Salomao K, Pereira PR, Campos LC, Borba CM, Cabello PH, Marcucci MC, et al. Brazilian propolis: correlation between chemical composition and antimicrobial activity. Evid Based Complement Alternat Med. 2008;5:317-24.

28- Santiago SL, Pereira JC, Martineli AC. Effect of commercially available and experimental potassium oxalate-based dentin desensitizing agents in dentin permeability: influence of time and filtration system. Braz Dent J. 2006;17:300-5.

29- Tay FR, Pashley DH, Mak YF, Carvalho RM, Lai SC, Suh BI. Integrating oxalate desensitizers with total-etch two-step adhesive. J Dent Res. 2003;82:703-7.

30- Walters PA. Dentinal hypersensitivity: a review. J Contemp Dent Pract. 2005;6:107-17. 